\title{
Nötrofil, Platelet, Eosinofil/Lenfosit Oranları ve MPV'nin Efüzyonlu Otitis Media Tanısında Gerçekten Potansiyel Rolï Var mı?
}

\author{
Are Neutrophil, Platelet, and Eosinophil-to-Lymphocyte Ratio and Mean Platelet \\ Volume Really Potential Predictor for Otitis Media with Chronic Effusion? \\ Oğuz Kadir Eğilmez, Mehmet Güven, Mahmut Sinan Yılmaz, Deniz Demir, Bilgehan Çelik \\ Sakarya Üniversitesi Eğitim ve Araştırma Hastanesi, KBB Ana Bilim Dal, Sakarya
}

Yazışma Adresi / Correspondence:

Oğuz Kadir Eğilmez

Sakarya Üniversitesi Eğitim ve Araştırma Hastanesi, KBB Anabilim Dalı, Korucuk Kampüs 3. Kat, Adapazarı, Sakarya

T: +905073447764 E-mail: : oguzegilmez@gmail.com

Geliş Tarihi / Received : 12.01.2019 Kabul Tarihi / Accepted : 20.05.2019

Orcid :

Oğuz Kadir Eğilmez https://orcid.org/0000-0001-9623-9152

Mehmet Güven https://orcid.org/0000-0002-3665-2428

Mahmut Sinan Yılmaz https://orcid.org/0000-0002-5323-0059

Deniz Demir https://orcid.org/0000-0001-7914-2201

Bilgehan Çelik https://orcid.org/0000-0003-4762-0242

Bu çalışma 31 Mayıs-3 Haziran 2018 tarihinde Varna, Bulgaristan'da gecçekleştirilen XI. Otorinolaringoloji Balkan Kongresi’nde poster bildirisi olarak sunulmuştur.

$\ddot{\mathrm{O} z}$

Amaç Efüzyonlu otitis media (EOM), orta kulakta sıvı birikimi ile karakterize inflamatuar bir hastalıktır. Bu çalışmanın amacı, EOM’li erişkin hastalarda nötrofil, platelet ve eozinofil-lenfosit oranı ve ortalama platelet hacminin prediktif rolünü araștırıp kontrol denekleri ile karșılaștırmak ve hastalığın ilerlemesini tahmin etmek için potansiyel bir belirleyici parametre olup olmadığını analiz etmektir. ( Sakarya Tıp Dergisi 2019, 9(2):297-301 )

Gereç ve "Vaka-kontrol çalıșması" șeklinde planlanan çalıșmamızda 18-50 yaşları arasında effüzyonlu kronik otitis media'lı 69 hasta (44 erkek, 25 kadın) ve yaș ve cinsiyet Yöntemler eșleștirilmiş 69 sağlıklı kontrol denek (yaş aralığı 18-50; 38 erkek, 31 kadın) retrospektif olarak incelendi. Çalışma ve kontrol grupları, MPV, nötrofil-lenfosit, trombositlenfosit ve eozinofil-lenfosit oranları için birbirleriyle karşılaștırıldı.

Bulgular Hasta grubunda NLR, PLR, ELR ve MPV değerleri sırası ile 1,97; 112,69; 0,08 ve 7,75 olarak saptanırken kontrol grubunda sirasi ile 1,90; 114,$58 ; 0,06$ ve 7,62 olarak bulundu ve gruplar arasinda istatistiksel olarak anlamlı fark saptanmadı (sırasıyla $\mathrm{p}=0.646,0.843,0.16,0.769$ ).

Sonuç Literatürde her ne kadar aksini belirten çalıșmalar olsa da biz EOM tanısında bu değerlerin prediktif bir değerinin olmadığını düssunmekteyiz. Fazla sayıda denekle ileri çalıșmalara ihtiyaç olduğu açıktır.

Anahtar efüzyonlu otitis media; nötrofil/lenfosit oranı; platelet/lenfosit oranı; eosinofil/lenfosit oranı; MPV

Kelimeler

Abstract

Objective Otitis media with effusion is an inflammatory disease characterized by fluid accumulation in the middle ear. The aim of this study is to investigate the predictive role of neutrophil, platelet, and eosinophil-to-lymphocyte ratio and mean platelet volume in adult patients having otitis media with effusion and to compare with control subjects; analyse whether they could be a potential predictor parameter to predict the disease progression. ( Sakarya Med J 2019, 9(2):3297-301).

Materials In our study which was planned as "case-control study", we retrospectively analyzed 69 patients (44 male, 25 female) between the ages of 18-50 having only chronic otitis media with effusion, and Methods and 69 age- and sex matched (between ages of 18-50; 38 male, 31 female) healthy controls. Study and control groups were compared with each other for MPV, neutrophil-to-lymphocyte, platelet-to-lymphocyte, and eosinophil-to-lymphocyte ratios.

Results NLR,PLR, ELR and MPV values in the patient group were 1.97, 112.69, 0.08 and 7.75 and the mean value of the control group was 1.90, 114.58, 0.06 and 7.62, respectively. There was no statistically significant difference between the groups ( $p=0.646,0.843,0.16,0.769$, respectively).

Conclusion Although there are other studies in the literature, we think that these values do not have a predictive value in the diagnosis of EOM. It is clear that further studies with large numbers of subjects are needed.

Keywords otitis media with effusion; neutrophil / lymphocyte ratio; platelet / lymphocyte ratio; eosinophil /lymphocyte ratio; MPV 


\section{GIIRIŞ}

Efüzyonlu otitis media (EOM), orta kulakta sıvı birikimi ile karakterize inflamatuar bir hastalıktır. Total beyaz küre ve alt tipleri sayımı ve bunların oranları (Nötrofil, Platelet, Eosionofil-Lenfosit oran1; NLR, PLR, ELR oranı) son zamanlarda kronik inflamasyonun bir göstergesi olarak kullanılmaktadır. ${ }^{1-6}$ Nötrofiller, miyeloperoksidaz, asit fosfataz ve elastaz gibi doku yıkımı serbest birakma enzimleri tarafından aktive edilir. Enflamatuvar reaksiyon sırasında dolaşımdaki lökositlerin oranı değişir. Nötrofiliye rölatif lenfopeni eşlik eder. Literatürde, NLR ve PLR'nin kardiyovasküler hastalıklar ve diyabetes mellitus, hipertansiyon, hepatik siroz, ailesel Akdeniz ateşi ve malignitelerde prognostik öneme sahip olduğu öne sürülmüştür. ${ }^{7}$ ERL ayrıca alerjik reaksiyonlarla ilgili hastalıklarla da ilişkilidir. ${ }^{8}$ Ortalama trombosit hacmi (MPV) ölçümü ise, periferik kandaki trombositlerin büyüklügüne dayanmaktadır; trombosit aktivasyonunun kolayca bulunabilen bir belirtecidir ve protrombotik ve pro-enflamatuar marker olarak kullanılmaktadır. ${ }^{9}$ Bu çalışmanın amacı, EOM bulunan erişkin hastalarda NLR, PLR, ELR oranları ve MPV'nin prediktif rolünü araştırmak ve kontrol denekleri ile karşılaştırmak; hastalığın ilerlemesini tahmin etmek için potansiyel bir belirleyici parametre olup olmadığını analiz etmektir.

\section{GEREÇ ve YÖNTEMLER}

Çalışmaya Ocak 2015 ile Şubat 2018 arasında kliniğimize başvuran 18-50 yaşları arasında sadece efüzyonlu kronik otitis mediaya sahip 69 hasta (44 erkek, 25 kadın) ve yaş ile cinsiyet eşleştirilmiş (yaşları 18-50; 38 erkek, 31 kadın) 69 sağlıklı kontrol hastası dahil edildi. Hasta ve kontrol grubunun arşiv dosyaları retrospektif olarak incelendi. Çalışmanın etik kurulu onayı lokal etik kurulundan alındıktan sonra çalışmaya başlandı ve çalışmanın tipi "vaka-kontrol çalışması" olarak belirlendi.

Otoskopik muayenede efüzyon ve buna bağlı olarak tip-B timpanogram eğrisi bulunan hastalar ve ayrıca fleksible nazofaringoskopide ek patoloji saptanmayan hastalar çalışmaya dahil edildi. Akut enfeksiyon, tip-B olmayan timpanogram eğrisi, kronik hastalık ve retraksiyonu olan hastalar çalışma dışı bırakıldı. Çalışma grubunun sonuçları ve kontrol grupları MPV, NRL, PRL ve ERL için karşılaştırıldı.

İstatistiksel yöntemler için, değişkenlerin dağılımı Kolmogorov-Smirnov testi ile ölçülmüştür. Kalitatif verilerin analizinde Mann-Whitney $U$ testi ve kantitatif veri analizi için $\mathrm{x} 2$ testi kullanılmıştır. Analiz SPSS v22.0 yazılım programı ile yapılmıştır. p 0.05 den küçük değerler istatistiksel olarak anlamlı olarak değerlendirilmiştir.

\section{BULGULAR}

EOM hasta grubunda 44 erkek 25 kadın toplam 69 hasta yer almaktaydı. Bu grupta ortalama yaş erkek, kadın ve toplamda sirasi ile $37,68 \pm 8,93 ; 33,40 \pm 10,93$ ve $36,13 \pm 9,80$ idi (Tablo-1). Kontrol grubu 38'i erkek 31'i kadın toplam 69 hastadan oluşmakta idi. Bu grubun yaş ortalaması sırası ile $36,52 \pm 9,01 ; 33,29 \pm 9,77$ ve 35,07 $\pm 9,60$ idi (Tablo-1). İki grup arasında yaş, cinsiyet ve sayı olarak istatistiksel olarak anlamlı fark yoktu ( $\mathrm{p}>0,05$, Tablo-1).

\begin{tabular}{|l|c|c|c|c|c|}
\hline \multicolumn{2}{|l|}{ Tablo-1 Hastaların demografik bulguları } \\
\hline & & $\begin{array}{c}\text { Efüzyonlu } \\
\text { otitis media }\end{array}$ & & Kontrol grubu & p değeri \\
\hline & $\mathrm{n}$ & Ort. \pm SD (yaş) & $\mathrm{n}$ & Ort. \pm SD (yaş) & \\
\hline Erkek & 44 & $37,68 \pm 8,93$ & 38 & $36,52 \pm 9,01$ & $>0,05$ \\
\hline Kadın & 25 & $33,40 \pm 10,93$ & 31 & $33,29 \pm 9,77$ & $>0,05$ \\
\hline Total & 69 & $36,13 \pm 9,80$ & 69 & $35,07 \pm 9,60$ & $>0,05$ \\
\hline
\end{tabular}

EOM hasta grubunun kontrol grubu ile NLR, PLR, ERL ve MPV değerleri açısından karşılaştırılması sonucunda hasta grubunda değerler sirası ile 1,97; 112,69; 0,08 ve 7,75 olarak saptanırken kontrol grubunda sırası ile 1,90; 114,58; 0,06 ve 7,62 olarak saptand. Bu bulguların istatiksel olarak p değerleri sırası ile 0,$646 ; 0,843 ; 0,160$ ve 0,769 olup hiçbir grupta istatistiksel olarak anlamlı bir sonuç saptanmadı (Tablo-2). 


\begin{tabular}{|c|c|c|c|}
\hline \multicolumn{4}{|c|}{$\begin{array}{l}\text { Tablo-2 Efüzyonlu otitis media hasta grubunun kontrol grubu } \\
\text { ile NLR, PLR, ERL ve MPV değerleri açısından karşılaștırıl- } \\
\text { ması }\end{array}$} \\
\hline & $\begin{array}{l}\text { Efüzyonlu } \\
\text { Otitis Media }\end{array}$ & Kontrol & $\mathrm{p}$ değeri \\
\hline $\begin{array}{l}\text { Nötrofil- } \\
\text { lenfosit oranı }\end{array}$ & $1,97(0,53-6)$ & $1,90(0,79-6,26)$ & 0,646 \\
\hline $\begin{array}{l}\text { Platelet- } \\
\text { lenfosit oranı }\end{array}$ & $\begin{array}{c}112,69 \\
(11,45-256,55)\end{array}$ & $\begin{array}{c}114,58 \\
(40,14-309,57)\end{array}$ & 0,843 \\
\hline $\begin{array}{l}\text { Eozinofil- } \\
\text { lenfosit oranı }\end{array}$ & $0,08(0,01-0,42)$ & $0,06(0,01-0,24)$ & 0,16 \\
\hline $\begin{array}{l}\text { MPV } \\
\text { (Mean platelet } \\
\text { volume) }\end{array}$ & $7,75(5,7-12,6)$ & $7,62(5,43-9,90)$ & 0,769 \\
\hline
\end{tabular}

TARTIŞMA

NLR ve PLR değerleri son yıllarda tanımlanan inflamatuar parametreler olup periferik kan analizinden kolaylıkla hesaplanabilir. Yüksek NLR ve PLR'nin, inflamasyonun şiddeti ile ilişkili olduğu bildirilmiştir. ${ }^{10}$ EOM'de efüzyon gelişiminden genellikle östaki disfonksiyonu sorumlu tutulmasına rağmen, inatçı enfeksiyon ve inflamasyonun da bu süreçte rol oynadığı bilinmektedir. ${ }^{11}$ Bunu destekler nitelikte Yellon ve ark. yaptığı EOM ve inflamasyon ilişkisine odaklanan bir çalışmada, EOM'li çocuklarda interlökin-1-beta, interlökin-2 ve tümör nekroz faktörü-alfa düzeyleri kontrol grubundaki çocuklardan daha yüksek saptanmıştır. ${ }^{12}$ Ayrıca Smirnova ve arkadaşları, EOM'li çocuklarda araşidonik asit metabolitlerinin ve proinflamatuar sitokinlerin anlamlı derecede yüksek olduğunu göstermiştir. ${ }^{13}$ Buradan yola çıkarak hastaların hemogram tetkiklerinden kolayca hesaplanabilen, ucuz maliyetli, inflamatuar hadiseleri göstermede rol oynadığı düşünülen NLR, ELR, PLR ve MPV değerlerinin kontrol grupları ile karşılaştırıldığ çok sayıda çalışma yürütülmüştür.

NLR'den iki farklı bağışıklık yolu hakkında bilgi alabiliriz. İlk olarak, kalıcı inflamasyondan sorumlu olan nötrofilleri değerlendirebiliriz ve ikinci olarak düzenleyici yoldaki lenfositleri değerlendirebiliriz. Sistematik inflamatuar cevap özelliği, dolaşımdaki beyaz kan hücrelerinin göreceli seviyelerine göre değişir. Nötrofiliye rölatif lenfositopeni eşlik eder. ${ }^{10}$ Ayrıca plateletler de doğal ve adaptif bağışıklık sistemleri arasında aracılık görevi görebilir. İnflamatuar bölgelerde aktive edildiklerinde, hücre içi granüllerinde bulunan yüksek seviyede pro-enflamatuar maddeleri dışarı salgılarlar. Hemostazdaki rollerinin ötesinde güçlü proinflamatuar hücreler olarak rolleri olduğu fikrini destekleyen sağlam kanıtlar vardır. ${ }^{14}$ Ek olarak, PLR seviyeleri bize inflamasyon süreci hakkında bilgi verebilir. ${ }^{10}$

Ortalama trombosit hacmi (MPV), tam kan sayımında rutin olarak bildirilen parametrelerden biridir ve seviyesi kronik enflamasyonda artabilir veya azalabilir. Bu değer trombositlerin büyüklüğü hakkında bilgi verir. Trombositlerdeki inflamatuar ve trombotik sitokinler MPV arttıkça artar. Önceki çalışmalar, miyokard enfarktüsü, inme, venöz tromboembolizm, ankilozan spondilit ve kronik ürtiker dahil olmak üzere çeşitli inflamatuar ve kardiyovasküler hastalıklarda artmış MPV seviyelerini göstermiștir. ${ }^{9}$ Atan ve arkadaşları 77 hasta ile yürüttükleri bir çalışmada NLR ve PLR'nin EOM'de yüksek olduğunu saptamışlardır. ${ }^{15}$ Boztepe ve ark., 81 hasta üzerinde bir çalışma yürütmüş ve orta kulak efüzyonlarında NLR'nin anlamlı olarak arttığını ve 1.38 'lik oranın çalışmalarında hesaplanan cutoff değeri olduğunu bildirmişlerdir. ${ }^{16}$ Yüz yirmi altı hasta ile 124 kontrol grubunun karşılaştırıldığ mada da NLR ve PLR'nin anlamlı derecede yüksek olduğu gösterilmiştir. ${ }^{10}$ Bizim çalışmamızda bu değerler kontrol grubu ile karşılaştırıldığında daha yüksek olduğu görülmektedir. Bu da inflamasyonun EOM patofizyolojisindeki önemini destekler niteliktedir. Fakat değerler istatistiksel olarak değerlendirildiğinde kontrol grubu ile anlamlı bir fark saptanamamıştır. Bundan dolayı kolay hesaplanabilen bir ölçüt olsa da elde edilen sonuçlara güvenerek EOM tayini yapılmamalı, bu sonuçları destekler nitelikte daha objektif tetkikler mutlaka yapılmalıdır.

Literatürde bu konuyla ilgili yapılan daha önceki çalışmalar pediatrik hasta popülasyon üzerinde yapılmış olup bildiğimiz kadarıyla bizim çalışmamız erişkin yaş hasta grubu ile yapılan ilk çalışmadır. Fakat çalışmamızda bazı kısıtlamalar da mevcuttur. Yürüttügümüz bu çalışma hasta dosyaları taranarak retrospektif olarak tamamlandığ 1 
için ve hasta dosyalarına opere edilen hastaların timpanik membrana yapılan parasentez sonrası orta kulaktan aspire edilen sıvının yoğunluğu not edilmemiş olduğundan, hasta grubu sıvının yoğunluğuna göre ayrı ayrı (seröz-müköz) gruplandırılamamıştır. Halbuki daha önce yapılan bazı çalışmalarda hastalar sıvının yoğunluğuna göre de gruplandırılmış ve değerler karşılaştırıldığında bozulmuş sıvı emiliminin bir göstergesi olan düşük viskoziteli hastalarda, daha belirgin bir inflamasyon geliştiği; yani seröz orta kulak sıvısı olanlarda daha fazla inflamasyon oluştuğu gösterilmiş ve müköz sıvı oluşmasında ise enfeksiyon ve inflamasyon yerine östaki tüpü disfonksiyonun daha çok neden olduğu hipotez edilmiştir. ${ }^{10}$

\section{SONUÇ}

EOM hasta grubu kontrol grubu ile NLR, PLR, ELR ve MPV değerleri açısından karşılaştırıldığında, tüm gruplar için istatistiksel olarak anlamlı bir fark bulunamadı. Literatürde; daha önceki bazı çalışmalarda bu değerlerin hastalıkların tanısında prediktif bir değer olarak kullanılabileceği öngörülse de, bunu açıklığa kavuşturmak için daha detaylı çalışmalara ihtiyaç olduğu açıktır. Sonuçlarımız göz önünde bulundurulduğunda, dikkat edilmesi ve hastalık tahmini ile ilgili sadece bu sonuçların dikkate alınmaması gerektiği aşikardır.

\section{Çıkar İlişkisi}

Çalışmamızda herhangi bir çıkar çatışması yoktur. 
Sakarya Tip Dergisi 2019;9(2):297-301

EĞILMEZ ve Ark. NRL, PLR, ELR, MPV ve Efüzyonlu Otitis Media

\section{Kaynaklar}

1. Kim HS, Jung J, Dong SH, Kim SH, Jung SY, Yeo SG. Association Between High Neutrophil to Lymphocyte Ratio and Delayed Recovery From Bell's Palsy. Clin Exp Otorhinolaryngol. 2018; 15. doi: 10.21053/ceo.2018.01018. [Epub ahead of print]

2. Angkananard T, Anothaisintawee T, McEvoy M, Attia J, Thakkinstian A. Neutrophil Lymphocyte Ratio and Cardiovascular Disease Risk: A Systematic Review and Meta-Analysis. Biomed Res Int. 2018; 11;2018:2703518. doi: 10.1155/2018/2703518.

3. Mochimaru T, Ueda S, Suzuki Y, Asano K, Fukunaga K. Neutrophil to lymphocyte ratio is a novel independent predictor of severe exacerbation in asthma patients. Ann Allergy Asthma Immunol. 2018; 30. pii: S1081-1206(18)31500-X. doi: 10.1016/j.anai.2018.11.029. [Epub ahead of print]

4. Renaud S, Seitlinger J, St-Pierre D, Garfinkle R, Al Lawati Y, Guerrera F, et al. Prognostic value of neutrophil to lymphocyte ratio in lung metastasectomy for colorectal cancer. Eur $J$ Cardiothorac Surg. 2018; 1. doi: 10.1093/ejcts/ezy388. [Epub ahead of print]

5. Hasselbalch IC, Søndergaard HB, Koch-Henriksen N, Olsson A, Ullum H, Sellebjerg F, et al. The neutrophil-to-lymphocyte ratio is associated with multiple sclerosis. Mult Scler J Exp Transl Clin. 2018; 28:4:2055217318813183. doi: 10.1177/2055217318813183.

6. Cho Y, Kim JW, Yoon HI, Lee CG, Keum KC, Lee IJ. The Prognostic Significance of Neutrophil-to-Lymphocyte Ratio in Head and Neck Cancer Patients Treated with Radiotherapy. J Clin Med. 2018; 3:7. pii: E512. doi: 10.3390/jcm7120512.

7. Kara A, Guven M, Yilmaz MS, Demir D, Elden H. Are neutrophil, platelet and eosinophil-to-lymphocyte ratio and red blood cell distribution width can be used for nasal polyposis? Eur Arch Otorhinolaryngol. 2018; 275:409-413. doi: 10.1007/s00405-017-4821-3.

8. Yenigun A, Sezen S, Calim OF, Ozturan O. Evaluation of the eosinophil-to-lymphocyte ratio in pediatric patients with allergic rhinitis. Am J Rhinol Allergy. 2016; 30:e21-5. doi: 10.2500/ ajra.2016.30.4296.
9. Eryilmaz MA, Derin S. Mean Platelet Volume as a Potential Predictor of Cholesteatoma in Children. J Craniofac Surg. 2016; 27:e575-8. doi: 10.1097/SCS.0000000000002881.

10. Elbistanli MS, Koçak HE, Acipayam H, Yiğider AP, Keskin M, Kayhan FT. The Predictive Value of Neutrophil-Lymphocyte and Platelet-Lymphocyte Ratio for the Effusion Viscosity in Otitis Media With Chronic Effusion. J Craniofac Surg. 2017; 28:e244-e247. doi: 10.1097/ SCS.0000000000003452.

11. Coates H, Thornton R, Langlands J, , Filion P, Keil AD, Vijayasekaran S, et al. The role of chronic infection in children with otitis media with effusion: evidence for intracellular persistence of bacteria. Otolaryngol Head Neck Surg 2008; 138:778-781

12. Yellon RF, Leonard G, Marucha PT, Craven R, Carpenter RJ, Lehmann WB, et al. Characterization of cytokines present in middle ear effusions. Laryngoscope 1991; 101:165-169

13. Smirnova MG, Kiselev SL, Gnuchev NV, J. P. Birchall, J. P. Pearson. Role of the proinflammatory cytokines tumor necrosis factor-alpha, interleukin-1 beta, interleukin-6 and interleukin-8 in the pathogenesis of the otitis media with effusion. Eur Cytokine Netw 2002; 13:161-172

14. Voudoukis E, Karmiris K, Koutroubakis IE. Multipotent role of platelets in inflammatory bowel diseases: a clinical approach. World J Gastroenterol. 2014; 28: 20:3180-90. doi: 10.3748/wjg.v20.i12.3180.

15. Atan D, Apaydin E, Ozcan KM, Dere H. New diagnostic indicators in chronic otitis media with effusion: neutrophil to lymphocyte ratio and thrombocyte lymphocyte ratio. ENT UPdates 2016;6:12-15

16. Boztepe OF, Demir M, Gün T, Bilal N, Ensari NA, Doğru H. A novel predictive marker for the viscosity of otitis media with effusion. Int J Pediatr Otorhinolaryngol. 2015; 79:23552358. doi:10.1016/j.ijporl.2015.10.043. 